(c) The Authors 2019. This is an Open Access article, distributed under the terms of the Creative Commons Attribution licence (http:// creativecommons.org/licenses/by/4.0/), which permits unrestricted re-use, distribution, and reproduction in any medium, provided the original work is properly cited.

\title{
Fish consumption and risk of incident dementia in elderly Japanese: the Ohsaki cohort 2006 study
}

\author{
Nozomu Tsurumaki, Shu Zhang*, Yasutake Tomata, Saho Abe, Yumi Sugawara, Sanae Matsuyama and \\ Ichiro Tsuji \\ The Division of Epidemiology, Department of Health Informatics and Public Health, Tohoku University School of Public Health, \\ Graduate School of Medicine, 2-1, Seiryo-machi, Aoba-ku, Sendai, Miyagi 980-8575, Japan
}

(Submitted 4 April 2019 - Final revision received 26 August 2019 - Accepted 27 August 2019)

\section{Abstract}

Fish harbour many types of nutrients that are beneficial for preventing cognitive decline. Therefore, habitual fish intake might contribute to a lower risk of incident dementia. However, few prospective cohort studies have investigated fish consumption in relation to incident dementia, and their findings have been inconsistent. To investigate the association between fish consumption and the risk of incident dementia, we collected data on the consumption of fish and other foods using an FFQ in a baseline survey of individuals aged $\geq 65$ years living in Ohsaki City, Japan. After 5.7 years of follow-up, the incidence of dementia was 1118 (8.5\%) among 13102 participants. We then used a multivariate-adjusted Cox model to estimate hazard ratios (HR) and $95 \%$ CI. Compared with subjects with the lowest fish intake (Q1), the multivariate HR were $0.90(95 \%$ CI $0 \cdot 74,1 \cdot 11)$ for Q2, 0.85 (95\% CI 0.73, 0.99) for Q3 and 0.84 (95\% CI 0.71, 0.997) for Q4 $\left(P_{\text {trend }}=0.029\right)$. Such associations were also observed even after excluding participants who were diagnosed with dementia in the first 2 years of follow-up and those who had poorer cognitive function at baseline. In conclusion, an association was observed between higher fish consumption and a lower risk of incident dementia among healthy elderly people without disability. These findings suggest that habitual fish intake may be beneficial for the prevention of dementia.

Key words: Fish: Dementia: Prospective cohort studies: Elderly people: Japan

The worldwide incidence of dementia is increasing. According to a report from the WHO, $46 \cdot 8$ million people worldwide were living with dementia in 2015 , and this number is projected to reach 131.5 million by $2050^{(1)}$. In Japan, it is estimated that $33 \%$ of elderly Japanese (more than 1.1 million) will have dementia by $2060^{(2)}$. Currently, in the absence of effective treatment of dementia, prevention is the most important approach.

Previous studies have reported that various nutrients in fish may be beneficial for the neurological system and cognitive status $^{(3-11)}$. Fish contains $n-3$ fatty acids, such as EPA and DHA, which are suggested to have preventive effects against cognitive decline ${ }^{(3,4)}$. Other nutrients in fish, such as vitamin $\mathrm{A} /$ carotenoids ${ }^{(5,6)}$, vitamin $\mathrm{B}_{12}{ }^{(7,8)}$, vitamin $\mathrm{D}^{(9)}$, vitamin $\mathrm{E}^{(10)}$ and $\mathrm{Se}^{(11)}$, are also known to have neuroprotective effects.

In addition, previous studies regarding the anti-dementia effects of dietary patterns have reported that adherence to a Japanese dietary pattern ${ }^{(12)}$, a Mediterranean $\operatorname{diet}^{(13)}$ or a Mediterranean-Dietary Approaches to Stop Hypertension (DASH) Intervention for Neurodegenerative Delay diet ${ }^{(14)}$ is associated with a lower risk of incident dementia. In these dietary patterns, fish is a common food component. Therefore, considering this evidence, the habitual intake of fish could be expected to be associated with a lower risk of incident dementia.

To date, only five previous studies, to our knowledge, have investigated the associations between fish consumption and incident dementia; however, the findings were inconsistent ${ }^{(4,15-18)}$. Four of these studies (conducted in the $\mathrm{USA}^{(4,15)}$, France ${ }^{(18)}$ and the Netherlands $\left.{ }^{(17)}\right)$ reported a non-significant inverse association between fish intake and incident dementia, whereas only one study ${ }^{(16)}$ observed a lower risk of incident dementia with a higher amount of fish consumption. These inconsistencies may be attributable to differences in the numbers of participants and dementia cases, the length of follow-up (studies with shorter follow-up tended to show an inverse association, while those with longer follow-up found no association), or differences in fish consumption among the studied populations.

Japanese people have the highest per capita consumption of seafood in the world, with oily fish such as salmon, tuna,

Abbreviations: HR, hazard ratio; LTCI, long-term care insurance.

* Corresponding author: Shu Zhang, fax +81-22-717-8125, email zhangshu@med.tohoku.ac.jp 
amberjack and Pacific saury the most commonly consumed in daily life ${ }^{(19)}$. Therefore, the association between fish consumption and the onset of dementia in Japan should be investigated. To our knowledge, however, no report on this topic has yet been published.

The aim of the present study was to investigate the association between fish consumption and the incident risk of dementia among a Japanese population.

\section{Methods \\ Study cohort}

The design of the Ohsaki Cohort 2006 Study has been described in detail elsewhere ${ }^{(20)}$. In brief, the source population for the baseline survey comprised 31694 men and women aged $\geq 65$ years living in Ohsaki city, northeastern Japan, on 1 December 2006. The baseline survey was conducted between 1 December and 15 December 2006 and follow-up started on 1 April 2007 and ended on 30 November 2012. In the baseline survey, a questionnaire was distributed by the heads of individual administrative districts to individual households and then collected by mail. In this analysis, 23091 persons who provided valid responses formed the study cohort (Fig. 1). We excluded 6333 persons who did not provide written consent for review of their long-term care insurance (LTCI) information, 2102 who had already been certified as having disability by the LTCI system before follow-up (1 April 2007), sixty-two who had died or moved out of the district before follow-up, 192 whose Doctor's Opinion Paper or cognitive status in the Doctor's Opinion Paper was unavailable and 1300 whose fish consumption data were missing. Thus, 13102 individuals were analysed for the purposes of the present study. During the 5.7-year follow-up period, only 122 persons were lost because of moving out of the study area without developing incident disability, resulting in a follow-up rate of $99.1 \%$. For the 64931 total person-years, incident dementia was determined for 1118 persons ( $8.5 \%$ of all participants) and $862(6.6 \%)$ deaths were observed.

\section{Consumption of fish and other foods}

We asked about the consumption frequency of fish and other food items using a valid FFQ. The FFQ included thirty-nine food items and several beverages. The term 'fish' referred to two food items: (1) raw fish/fish broiled with soya/grilled fish and (2) boiled fish paste. The term 'green and yellow vegetables' was defined as the sum of five food items (i.e. green vegetables, carrot and pumpkin, tomato, cabbage and lettuce and Chinese cabbage), and the term 'fruits' referred to three food items (i.e. citrus fruits, fruits except for citrus fruits and fresh juice). For each food item, five frequency categories were applied (almost never, 1-2 times/month, 1-2 times/week, 3-4 times/week and almost every day).

Next, we conducted a validation study of the FFQ by administering questionnaires to 113 individuals twice, 1 year apart, in November 1996 (FFQ1) and in November 1997 (FFQ2) ${ }^{(21)}$. We also collected a total of $12 \mathrm{~d}$ of records on 3 consecutive days (3-d diet records) four times in the year, in November

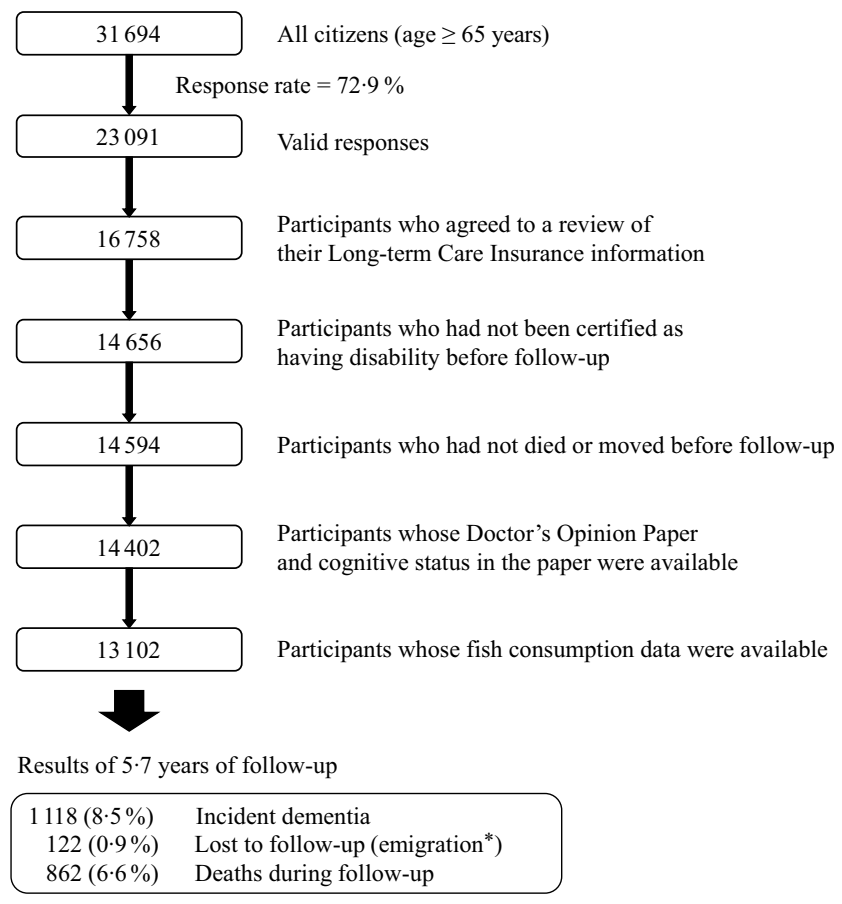

Fig. 1. Flow chart of the study participants: the Ohsaki Cohort 2006 Study. * Without developing incident disability.

1996 and in February, May and August 1997. Spearman correlation coefficients were estimated using an attenuated age- and energy-adjusted model. For raw fish/fish broiled with soya/ grilled fish, the Spearman rank correlation coefficients between the consumption frequency (in times/d) according to the FFQ and consumption volume (in grams) according to the dietary records were 0.39 for men and 0.60 for women, and for boiled fish paste, the corresponding values were 0.49 for men and 0.41 for women.

To assess fish consumption, we converted the consumption frequency from the FFQ into a daily intake volume (g/d). Daily intake was calculated by multiplying the average number of daily servings (times/d) transformed to an assigned portion size ( $\mathrm{g} /$ time) from the FFQ based on the dietary records in the validity study ${ }^{(21)}$. We then summed the daily intake of the two fish items (raw fish/fish broiled with soya/grilled fish and boiled fish paste) and used this value to represent fish consumption. The daily fish consumption volume was categorised into the following quartile groups: Q1 (the lowest), Q2, Q3 and Q4 (the highest).

\section{Covariates}

BMI was calculated as the self-reported body weight (in $\mathrm{kg}$ ) divided by the square of the self-reported body height (in $\mathrm{m}$ ).

For history of disease, we asked 'Which disease(s) did(do) you have?', with the answers set as 'stroke, hypertension, myocardial infarction, diabetes and hyperlipidaemia (yes or no for each term)'. Education level was assessed as 'How old were you when you completed your education?' and answered using a positive integer. Smoking status was assessed as 'Do you smoke?', with the answers set as (1) I smoke, (2) I used to smoke but quit and (3) I have never smoked. Alcohol 
drinking was assessed as 'Do you drink?', with the answers set as (1) I drink, (2) I used to drink but quit and (3) I have never drunk. Physical activity was assessed by time spent walking as 'How much time do you spend walking per day on average?', with the answers set as (1) $>1 \mathrm{~h} / \mathrm{d}$, (2) $0 \cdot 5-1 \mathrm{~h} / \mathrm{d}$ and $(3)<0.5 \mathrm{~h} / \mathrm{d}$. Sleep duration was assessed as 'How long do you sleep per day?', with the answers set as (1) $\leq 5 \mathrm{~h}$, (2) $6 \mathrm{~h}$, (3) $7 \mathrm{~h}$, (4) $8 \mathrm{~h}$, (5) $9 \mathrm{~h}$ and (6) $\geq 10 \mathrm{~h}$.

Scores on the Kessler six-item Psychological Distress Scale were used to indicate psychological distress ${ }^{(22,23)}$. Using six questions, respondents were asked about their mental status over the last month. Total scores ranged from 0 to 24 points. Based on the optimal cut-off point for mental illness in the validation study, we classified individuals with a score of $\geq 13$ as having psychological distress ${ }^{(23)}$.

The Kihon Checklist was developed by the Ministry of Health, Labour, and Welfare of Japan to predict functional decline in the community-dwelling elderly individuals. With regard to the Kihon Checklist cognitive function score, respondents were asked about their current cognitive function status using three binary questions, yielding total scores ranging from 0 to 3 points. The validity of the cognitive function score in the Kihon Checklist was confirmed in a previous study using the Clinical Dementia Rating as the 'gold standard'(24). A Kihon Checklist cognitive function score of 0 points was defined as better cognitive function.

\section{Follow-up (incident dementia)}

The primary outcome was incident dementia, defined as disabling dementia according to the criteria of the LTCI system used in Japan ${ }^{(25)}$.

The LTCI is a mandatory form of national social insurance to assist disabled elderly individuals carry out activities of daily living $^{(26-28)}$. Everyone aged $\geq 40$ years pays premiums, and everyone aged $\geq 65$ years is eligible for formal caregiving services under a uniform standard of disability certification. The procedure for disability certification consists of two parts: (1) assessment of the degree of functional disability using a questionnaire developed by the Ministry of Health, Labour, and Welfare and (2) reference to the Doctor's Opinion Paper prepared by the attending physician ${ }^{(29)}$.

Disabling dementia was defined as incident functional disability due to dementia according to the LTCI system, that is, dementia rank $\geq$ II on the Dementia Scale (Degree of Independence in Daily Living for Elderly with Dementia), as entered on the Doctor's Opinion Paper. The Dementia Scale is classified into six ranks ( 0 , I-IV and $M)$. Rank $M$ means that an individual has severe dementia-related behavioural disturbance that requires medical intervention. A rank over and equal to II is typically used as an outcome measure of incident dementia because individuals who have mild or moderate dementia are classified as rank $\mathrm{II}^{(25,30-32)}$. A previous study showed that the Dementia Scale is well correlated with the Mini Mental State Examination score (Spearman rank correlation coefficient $=-0.736)^{(33)}$

We obtained a data set that included information on LTCI certification, death or emigration from Ohsaki city. All data were transferred from the Ohsaki City Government under an agreement related to Epidemiologic Research and Privacy Protection.

\section{Ethical issues}

We considered the return of a completed questionnaire to imply consent to participate in the study, including the baseline survey data and subsequent follow-up of death and emigration. We also confirmed information regarding LTCI certification status after obtaining written consent, along with the questionnaires returned from the respondents at the time of the baseline survey. The Ethics Committee of Tohoku University Graduate School of Medicine (Sendai, Japan) reviewed and approved the study protocol.

\section{Statistical analysis}

We counted the person-years of follow-up for each respondent from 1 April 2007 until the date of incident dementia, date of emigration from Ohsaki city, date of death, date of incident functional disability without dementia or the end of the study period (30 November 2012), whichever occurred first. In our analysis, deaths without LTCI certification were treated as censored.

The multivariate-adjusted Cox proportional hazards model was used to estimate the hazard ratios (HR) and $95 \% \mathrm{CI}$ for incident dementia, according to fish consumption. Respondents who consumed the lowest amount of fish (Q1) were defined as a reference category. Multivariate models were adjusted for the following variables: model 1 was adjusted for age (65-69, $70-74,75-79,80-84$ or $\geq 85$ years) and sex. To examine whether the association between fish consumption and incident dementia was attributed to physical health status or other lifestyle-related factors, model 2 was further adjusted for BMI (in $\mathrm{kg} / \mathrm{m}^{2}$; $<18 \cdot 5,18 \cdot 5-25, \geq 25$ or missing), history of disease (stroke, hypertension, myocardial infarction, diabetes and hyperlipidaemia; yes or no for each term), education level (age at last school graduation: $<16,16-18, \geq 19$ years or missing), smoking (never, former, current or missing), alcohol drinking (never/ former, current or missing), time spent walking $(<1, \geq 1 \mathrm{~h} / \mathrm{d}$, or missing), sleep duration $(\leq 6,7-8, \geq 9 \mathrm{~h} / \mathrm{d}$ or missing), psychological distress score $(<13, \geq 13$ or missing) and cognitive function score $(0, \geq 1$ or missing). To adjust for the influence of other dietary factors, the consumption volumes of green and yellow vegetables and fruits (sex-specific tertile categories or missing) were added in model 3.

After applying the Cox proportional hazards model, the proportional hazards assumption was tested by a global goodnessof-fit test (assessing correlations between Schoenfeld residual of fish consumption groups and the rank of survival time).

Additionally, we conducted multiple imputations (by fully conditional specification ${ }^{(34)}$ ) for missing fish consumption values and all confounding factors in model 3 . The missing values were substituted with the most likely value by multiple imputations based on the observed values of those variables. We then created five output data sets and applied the Cox model 
Table 1. Baseline characteristics of the participants according to fish consumption ( $n$ 13 102) (Mean values and standard deviations; percentages)

\begin{tabular}{|c|c|c|c|c|c|}
\hline & \multicolumn{4}{|c|}{ Quartiles of fish consumption } & \multirow[b]{2}{*}{$P^{\star}$} \\
\hline & Q1 (lowest) & Q2 & Q3 & Q4 (highest) & \\
\hline \multicolumn{6}{|l|}{ Intake of fish $(\mathrm{g} / \mathrm{d})$} \\
\hline Mean & $20 \cdot 4$ & $44 \cdot 3$ & $57 \cdot 7$ & $96 \cdot 9$ & \\
\hline SD & $7 \cdot 7$ & 4.6 & 13.5 & $9 \cdot 0$ & \\
\hline No. of participants & 3225 & 1573 & 4304 & 4000 & \\
\hline \multicolumn{6}{|l|}{ Age (years) } \\
\hline Mean & $73 \cdot 8$ & 73.2 & 73.6 & 73.7 & $<0.001$ \\
\hline SD & $6 \cdot 2$ & $5 \cdot 8$ & 5.8 & $5 \cdot 7$ & \\
\hline Sex (males, \%) & 44.5 & $56 \cdot 5$ & $36 \cdot 5$ & $49 \cdot 1$ & $<0.001$ \\
\hline \multicolumn{6}{|l|}{ BMI $\left(\mathrm{kg} / \mathrm{m}^{2}\right)$} \\
\hline Mean & $23 \cdot 6$ & 23.5 & $23 \cdot 6$ & $23 \cdot 6$ & $<0.001$ \\
\hline SD & 3.6 & 3.1 & 3.3 & 3.2 & \\
\hline \multicolumn{6}{|l|}{ Medical history (\%) } \\
\hline Stroke & 3.5 & $2 \cdot 5$ & $2 \cdot 8$ & $2 \cdot 3$ & 0.031 \\
\hline Hypertension & $43 \cdot 2$ & 43.5 & 43.4 & 44.4 & 0.711 \\
\hline Myocardial infarction & 5.4 & 5.5 & 3.9 & $5 \cdot 0$ & 0.011 \\
\hline Diabetes & $12 \cdot 0$ & 13.5 & 11.0 & 11.9 & 0.079 \\
\hline Hyperlipidaemia & $7 \cdot 7$ & 9.5 & 9.5 & 8.5 & 0.030 \\
\hline Education level $<16$ years (\%) & $32 \cdot 9$ & $28 \cdot 1$ & $27 \cdot 7$ & $27 \cdot 3$ & $<0.001$ \\
\hline Current smoker (\%) & 14.9 & 17.4 & $10 \cdot 7$ & $13 \cdot 2$ & $<0.001$ \\
\hline Current alcohol drinker (\%) & $36 \cdot 8$ & $43 \cdot 2$ & 33.7 & 41.6 & $<0.001$ \\
\hline \multicolumn{6}{|l|}{ Sleep duration (\%) } \\
\hline$\leq 6 \mathrm{~h} / \mathrm{d}$ & $22 \cdot 7$ & $20 \cdot 9$ & $20 \cdot 0$ & $16 \cdot 9$ & $<0.001$ \\
\hline $7-8 \mathrm{~h} / \mathrm{d}$ & $56 \cdot 2$ & 57.5 & $59 \cdot 1$ & $59 \cdot 9$ & \\
\hline$\geq 9 \mathrm{~h} / \mathrm{d}$ & $21 \cdot 1$ & $21 \cdot 7$ & 21.0 & $23 \cdot 2$ & \\
\hline Psychological distress (\%)† & $6 \cdot 1$ & 3.6 & 4.6 & 3.4 & $<0.001$ \\
\hline Better cognitive function (\%)‡ & $58 \cdot 0$ & 63.7 & $63 \cdot 5$ & $67 \cdot 7$ & $<0.001$ \\
\hline Time spent walking $\geq 1 \mathrm{~h} / \mathrm{d}(\%)$ & $24 \cdot 7$ & $27 \cdot 7$ & $26 \cdot 3$ & 31.0 & $<0.001$ \\
\hline \multicolumn{6}{|l|}{ Intake $(\mathrm{g} / \mathrm{d})$} \\
\hline \multicolumn{6}{|l|}{ Green and yellow vegetables } \\
\hline Mean & 71.6 & $85 \cdot 1$ & 98.9 & $112 \cdot 6$ & $<0.001$ \\
\hline & 44.7 & $42 \cdot 9$ & 43.9 & $46 \cdot 8$ & \\
\hline \multicolumn{6}{|l|}{ Fruits } \\
\hline Mean & $112 \cdot 7$ & $122 \cdot 0$ & 148.5 & $167 \cdot 2$ & $<0.001$ \\
\hline SD & 88.4 & 84.3 & 89.1 & 93.1 & \\
\hline
\end{tabular}

* Obtained using the $\chi^{2}$ test for variables of proportion and one-factor ANOVA for continuous variables.

$\dagger$ Kessler six-item Psychological Distress Scale score $\geq 13$.

$\ddagger$ Better cognitive function score of the Kihon Checklist $=0$.

separately to obtain five sets of HR and 95\% CI. Finally, we integrated the pooled HR and $95 \%$ CI.

Considering possible reverse causality, we analysed whether the association would change if only individuals who had better cognitive function at baseline were selected. We also conducted another sensitivity analysis by excluding participants whose dementia event occurred within the first 2 years of follow-up.

We also conducted a competing risk regression analysis using death as the competitive event. We modelled the cumulative incidence function by defining the sub-distribution hazards, onto which we imposed the proportional hazards assumption ${ }^{(35)}$.

Finally, we performed tests of interaction to investigate the differences in the association between fish consumption and incident dementia in terms of sex, age ( $<75$ or $\geq 75$ years), consumption volume of green and yellow vegetables plus fruits (<median or $\geq$ median), education level (age at last school graduation: $<16$ or $\geq 16$ years), time spent walking $(<1$ or $\geq 1 \mathrm{~h} / \mathrm{d})$ and sleep duration $(\leq 6,7-8$ or $\geq 9 \mathrm{~h} / \mathrm{d})$. The $P$ value for interaction in the stratified analysis was computed by entering an interactive term (i.e. cross product) into the Cox model, which was created by multiplying fish consumption and sex, age, consumption volume of green and yellow vegetables plus fruits, education level, time spent walking and sleep duration. The exposure categories were treated as a continuous term (score variable $1,2,3$ or 4 ).

All of the above analyses were performed using SAS version 9.4 (SAS Inc.). All statistical tests described here are accompanied by the exact $P$ value.

The calculations showed that the sample size and the number of incident dementia cases in the Ohsaki study were sufficiently large to detect an HR of 0.9 for the highest compared with the lowest quartile of fish intake, with a statistical power of $90 \%$ and a significance level of 5\% (estimated using STATA version 15 provided by StataCorp LLC).

\section{Results}

\section{Baseline characteristics}

The baseline characteristics of the 13102 participants according to the fish consumption categories are shown in Table 1. Participants with higher fish consumption were less likely to be $<16$ years of age at the time of completing their education 
Table 2. Association between fish consumption and incident dementia $(n 13102)^{\star}$ (Adjusted hazard ratios and $95 \%$ confidence intervals)

\begin{tabular}{|c|c|c|c|c|c|c|c|c|c|}
\hline & \multicolumn{8}{|c|}{ Quartiles of fish consumption } & \multirow[b]{2}{*}{$P_{\text {for trend }} \dagger$} \\
\hline & \multicolumn{2}{|c|}{ Q1 (lowest) } & \multicolumn{2}{|c|}{ Q2 } & \multicolumn{2}{|r|}{ Q3 } & \multicolumn{2}{|c|}{ Q4 (highest) } & \\
\hline Person-years & & 536 & & 913 & & 21452 & & 0029 & \\
\hline No. of incident dementia & & 336 & & 132 & & 344 & & 306 & \\
\hline Incidence rate/ 1000 person-years & & 1.6 & & $6 \cdot 7$ & & $16 \cdot 0$ & & $15 \cdot 3$ & \\
\hline Crude & 1.00 & Reference & $0.77 \ddagger$ & $0.63,0.94$ & 0.74 & $0.63,0.86$ & $0 \cdot 70$ & $0.60,0.82$ & $<0.001$ \\
\hline Model 1§ & 1.00 & Reference & 0.84 & $0.68,1.02$ & $0 \cdot 77$ & $0.66,0.89$ & 0.72 & $0.62,0.85$ & $<0.001$ \\
\hline Model 2ll & 1.00 & Reference & 0.89 & $0.73,1.09$ & 0.83 & $0.71,0.97$ & 0.81 & $0.69,0.95$ & 0.005 \\
\hline Model 3ף & 1.00 & Reference & 0.90 & $0.74,1.11$ & 0.85 & $0.73,0.99$ & 0.84 & $0.71,0.997$ & 0.029 \\
\hline
\end{tabular}

* Analysis by the Cox proportional hazards model.

† Probability value for trend was computed by entering the exposure categories as a continuous term (score variable: $1,2,3$ or 4 ) in the Cox model.

$\ddagger$ Adjusted hazard ratios and $95 \% \mathrm{Cl}$ (all such values).

§ Model 1 was adjusted for age $(65-69,70-74,75-79,80-84$ or $\geq 85$ years) and sex.

II Model 2 was adjusted as for model 1 plus BMI ( $<18.5,18 \cdot 5-25, \geq 25 \mathrm{~kg} / \mathrm{m}^{2}$ or missing), history of disease (stroke, hypertension, myocardial infarction, diabetes or hyperlipidaemia

(yes or no for each term)), education level (age at last school graduation: $<16,16-18, \geq 19$ years or missing), smoking (never, former, current or missing), alcohol drinking (never/former, current or missing), time spent walking ( $<1, \geq 1 \mathrm{~h} / \mathrm{d}$ or missing), psychological distress score $(<13, \geq 13$ or missing), cognitive function score ( $0, \geq 1$ or missing) and sleep duration $(\leq 6,7-8, \geq 9 \mathrm{~h} / \mathrm{d}$ or missing).

In Model 3 was adjusted as for model 2 plus consumption volumes of green and yellow vegetables, fruits (sex-specific tertile categories or missing).

Table 3. Association between fish consumption and incident dementia (excluding participants with poor cognitive function at baseline) ( $n$ 8097) ${ }^{*}$ (Adjusted hazard ratios and $95 \%$ confidence intervals)

\begin{tabular}{|c|c|c|c|c|c|c|c|c|c|}
\hline & \multicolumn{8}{|c|}{ Quartiles of fish consumption } & \multirow[b]{2}{*}{$P_{\text {for trend }} \dagger$} \\
\hline & \multicolumn{2}{|c|}{ Q1 (lowest) } & \multicolumn{2}{|c|}{ Q2 } & \multicolumn{2}{|r|}{ Q3 } & \multicolumn{2}{|c|}{ Q4 (highest) } & \\
\hline Person-years & & 9213 & & 099 & & 13721 & & 3671 & \\
\hline No. of incident dementia & & 114 & & 49 & & 142 & & 119 & \\
\hline Incidence rate/1000 person-years & & $12 \cdot 4$ & & .6 & & $10 \cdot 3$ & & 8.7 & \\
\hline Crude & 1.00 & Reference & $0.77 \ddagger$ & $0.55,1.07$ & 0.83 & $0.65,1.06$ & 0.70 & $0.54,0.90$ & 0.011 \\
\hline Model $1 \S$ & 1.00 & Reference & 0.84 & $0.60,1.18$ & 0.85 & $0.66,1.09$ & 0.69 & $0.53,0.89$ & 0.007 \\
\hline Model 2ll & 1.00 & Reference & 0.86 & $0.61,1.20$ & 0.85 & $0.66,1.09$ & 0.71 & $0.55,0.92$ & 0.012 \\
\hline Model 3ף & 1.00 & Reference & 0.88 & $0.63,1.24$ & 0.88 & $0.68,1.13$ & 0.75 & $0.57,0.99$ & 0.052 \\
\hline
\end{tabular}

* Analysis by the Cox proportional hazards model.

† Probability value for trend was computed by entering the exposure categories as a continuous term (score variable: $1,2,3$ or 4 ) in the Cox model.

$\ddagger$ Adjusted hazard ratios and $95 \% \mathrm{Cl}$ (all such values).

§ Model 1 was adjusted for age $(65-69,70-74,75-79,80-84$ or $\geq 85$ years) and sex.

II Model 2 was adjusted as for model 1 plus BMI ( $<18.5,18.5-25, \geq 25 \mathrm{~kg} / \mathrm{m}^{2}$ or missing), history of disease (stroke, hypertension, myocardial infarction, diabetes or

hyperlipidaemia (yes or no for each term)), education level (age at last school graduation: $<16,16-18, \geq 19$ years or missing), smoking (never, former, current or missing), alcohol drinking (never/former, current or missing), time spent walking ( $<1, \geq 1 \mathrm{~h} / \mathrm{d}$ or missing), psychological distress score ( $<13$, $\geq 13$ or missing), cognitive function score $(0, \geq 1$ or missing) and sleep duration $(\leq 6,7-8, \geq 9 \mathrm{~h} / \mathrm{d}$ or missing).

If Model 3 was adjusted as for model 2 plus consumption volumes of green and yellow vegetables, fruits (sex-specific tertile categories or missing).

and to have a sleep duration $<6 \mathrm{~h} / \mathrm{d}$ but were more likely to sleep $7-8 \mathrm{~h} / \mathrm{d}$, to have better cognitive function, to spend more time walking per $\mathrm{d}$ and to consume more green and yellow vegetables and fruits. No linear trend was found in terms of the means and standard deviations for age and BMI or in the proportion of males, history of disease, smoking and alcohol drinking status or psychological distress.

\section{Fish consumption and incident dementia}

In the present study, the fish consumption quartiles for men were Q1 (<34.1 g/d), Q2 (34.1-53.4 g/d), Q3 (53.4-96.4 g/d) and Q4 (>96.4 g/d), and for women, Q1 (<41.3 g/d), Q2 (41.3-45.7 g/d), Q3 $(45.7-85.7 \mathrm{~g} / \mathrm{d})$ and Q4 $(>85.7 \mathrm{~g} / \mathrm{d})$.

The association between fish consumption and incident dementia is shown in Table 2. In the crude model, in comparison with Q1 (participants with the lowest amount of fish consumption), the HR for incident dementia were 0.77 (95\% CI $0.63,0.94)$ for $\mathrm{Q} 2,0.74(95 \%$ CI $0.63,0.86)$ for $\mathrm{Q} 3$ and 0.70 (95\% CI $0.60,0.82)$ for Q4 (highest) $\left(P_{\text {trend }}<0.001\right)$.
Even after adjusting the covariates in model 3, the multivariate HR were $0.90(95 \%$ CI $0.74,1.11)$ for Q2, 0.85 (95\% CI 0.73 , 0.99) for Q3 and 0.84 (95\% CI 0.71, 0.997) for Q4 $\left(P_{\text {trend }}=0 \cdot 029\right)$. The protective effects for higher fish consumption were still observed when using multiple-imputed data (the pooled multivariate HR were 0.86 (95\% CI 0.69 , 1.06) for Q2, $0.84(95 \%$ CI $0.72,0.98)$ for Q3 and 0.84 (95\% CI $0 \cdot 63,1 \cdot 10)$ for Q4 ( $\left.P_{\text {trend }}=0 \cdot 017\right)$ (table not shown).

The proportional hazard assumption was not violated (correlation coefficient between the Schoenfeld residual of fish consumption groups and the rank of survival time $=0 \cdot 017$, $P=0 \cdot 57)$.

The possibility that the participants with poorer cognitive function at baseline might have consumed less fish led us to analyse the association after selecting only 8097 participants who had better cognitive function (cognitive function score on the Kihon Checklist $=0$ ), as shown in Table 3. The multivariate HR were 1.00 (reference) for Q1, 0.88 (95\% CI 0.63, 1.24) for $\mathrm{Q} 2,0.88(95 \% \mathrm{CI} 0.68,1.13)$ for $\mathrm{Q} 3$ and $0.75(95 \%$ CI $0.57,0.99)$ for Q4 in model $3\left(P_{\text {trend }}=0.052\right)$. 
Table 4. Associations between fish consumption and incident dementia (excluding participants whose dementia occurred in the first 2 years of follow-up) $(n 12778)^{*}$

(Adjusted hazard ratios and $95 \%$ confidence intervals)

\begin{tabular}{|c|c|c|c|c|c|c|c|c|c|}
\hline & \multicolumn{8}{|c|}{ Quartiles of fish consumption } & \multirow[b]{2}{*}{$P_{\text {for trend }} \dagger$} \\
\hline & \multicolumn{2}{|c|}{ Q1 (lowest) } & \multicolumn{2}{|c|}{ Q2 } & \multicolumn{2}{|r|}{ Q3 } & \multicolumn{2}{|c|}{ Q4 (highest) } & \\
\hline Person-years & & 5428 & & 379 & & 21337 & & 9938 & \\
\hline No. of incident dementia & & 236 & & 00 & & 233 & & 225 & \\
\hline Incidence rate/1000 person-years & & $15 \cdot 3$ & & $2 \cdot 7$ & & $10 \cdot 9$ & & $11 \cdot 3$ & \\
\hline Crude & 1.00 & Reference & $0.81 \ddagger$ & $0.64,1.03$ & 0.70 & $0.59,0.84$ & 0.72 & $0.60,0.87$ & $<0.001$ \\
\hline Model $1 \S$ & 1.00 & Reference & 0.87 & $0.69,1.11$ & 0.72 & $0.60,0.87$ & 0.73 & $0.61,0.88$ & $<0.001$ \\
\hline Model 2ll & 1.00 & Reference & 0.92 & $0.73,1.16$ & 0.77 & $0.64,0.92$ & 0.80 & $0.67,0.97$ & 0.006 \\
\hline Model 3ף & 1.00 & Reference & 0.94 & $0.74,1.19$ & 0.80 & $0.66,0.96$ & 0.85 & $0.70,1.04$ & 0.043 \\
\hline
\end{tabular}

* Analysis by the Cox proportional hazards model.

† Probability value for trend was computed by entering the exposure categories as a continuous term (score variable: $1,2,3$ or 4 ) in the Cox model.

$\ddagger$ Adjusted hazard ratios and $95 \% \mathrm{Cl}$ (all such values).

$\S$ Model 1 was adjusted for age (65-69, 70-74, 75-79, 80-84 or $\geq 85$ years) and sex.

II Model 2 was adjusted as for model 1 plus BMI ( $<18.5,18.5-25, \geq 25 \mathrm{~kg} / \mathrm{m}^{2}$ or missing), history of disease (stroke, hypertension, myocardial infarction, diabetes or hyperlipidaemia (yes or no for each term)), education level (age at last school graduation: $<16,16-18, \geq 19$ years or missing), smoking (never, former, current or missing), alcohol drinking (never/ former, current or missing), time spent walking $(<1, \geq 1 \mathrm{~h} / \mathrm{d}$ or missing), psychological distress score $(<13, \geq 13$ or missing), cognitive function score ( $0, \geq 1$ or missing) and sleep duration $(\leq 6,7-8, \geq 9 \mathrm{~h} / \mathrm{d}$ or missing).

If Model 3 was adjusted as for model 2 plus consumption volumes of green and yellow vegetables, fruits (sex-specific tertile categories or missing).

Table 5. Relationships between fish consumption and incident dementia (death competing risk model) ( $n 13$ 102)* (Adjusted hazard ratios and $95 \%$ confidence intervals)

\begin{tabular}{|c|c|c|c|c|c|c|c|c|c|}
\hline & \multicolumn{8}{|c|}{ Quartiles of fish consumption } & \multirow[b]{2}{*}{$P_{\text {for trend }} \dagger$} \\
\hline & \multicolumn{2}{|c|}{ Q1 (lowest) } & \multicolumn{2}{|r|}{ Q2 } & \multicolumn{2}{|r|}{ Q3 } & \multicolumn{2}{|c|}{ Q4 (highest) } & \\
\hline Event of interest (dementia) & \multicolumn{8}{|c|}{1118} & \\
\hline Competing event (death) & \multirow{2}{*}{\multicolumn{8}{|c|}{$\begin{array}{c}1227 \\
10757\end{array}$}} & \\
\hline Censored value & & & & & & & & & \\
\hline Multivariate-adjusted modelł & 1.00 & Reference & $0.92 \S$ & $0 \cdot 75,1 \cdot 14$ & 0.85 & $0.73,1.00$ & 0.85 & $0.72,1.01$ & 0.042 \\
\hline
\end{tabular}

* Analysis by the Cox proportional hazards model.

† Probability value for trend was computed by entering the exposure categories as a continuous term (score variable: $1,2,3$ or 4 ) in the Cox model.

$\ddagger$ Adjusted for the same covariates in model 3 of Table 2.

$\S$ Adjusted hazard ratios and $95 \% \mathrm{Cl}$ (all such values).

For the same reason, we also analysed the association after excluding 324 participants who developed dementia in the first 2 years of follow-up (Table 4). The multivariate HR in model 3 were 1.00 (reference) for Q1, $0.94(95 \%$ CI $0.74,1.19)$ for Q2, $0.80(95 \%$ CI $0.66,0.96)$ for Q3 and 0.85 (95\% CI $0.70,1.04)$ for Q4 $\left(P_{\text {trend }}=0.043\right)$.

\section{Competing risk analysis}

The results of the competing risk regression analysis are shown in Table 5. Again, an association between higher fish consumption and a lower risk of incident dementia was observed $\left(P_{\text {trend }}=0.042\right)$. The multivariate HR were 1.00 (reference) for Q1, $0.92(95 \%$ CI $0.75,1.14)$ for Q2, 0.85 (95\% CI $0.73,1.00)$ for Q3 and $0.85\left(95 \%\right.$ CI 0.72, 1.01) for Q4 $\left(P_{\text {trend }}=0.042\right)$.

\section{Stratified analyses}

We also conducted sensitivity analyses stratified for sex, age ( $<75$ or $\geq 75$ years), consumption volume of green and yellow vegetables plus fruits ( $<$ median or $\geq$ median), education level (age at last school graduation: $<16$ or $\geq 16$ years), time spent walking ( $<1$ or $\geq 1 \mathrm{~h} / \mathrm{d}$ ) and sleep duration $(\leq 6,7-8$ or $\geq 9 \mathrm{~h} / \mathrm{d}$ ). After adjusting for multivariate factors, the inverse association between fish consumption and incident dementia did not differ with regard to sex, age, consumption volume of green and yellow vegetables plus fruits, education level, time spent walking or sleep duration ( $\leq 6$ or $7-8 \mathrm{~h} / \mathrm{d}$ ) (the corresponding $P$ values for interaction between fish consumption and each factor were $0 \cdot 845,0.946,0 \cdot 191,0.898,0.392$ and 0.502 , respectively). The $P$ value for interaction between fish consumption and sleep duration (7-8 or $\geq 9 \mathrm{~h} / \mathrm{d}$ ) was 0.052 , suggesting that the association between fish consumption and incident dementia may differ between elderly individuals who have a normal compared with a long sleep duration (Table 6).

\section{Discussion}

In this prospective cohort study, we followed 13102 Japanese individuals aged $\geq 65$ years for 5.7 years to investigate the association between fish intake and the incident risk of dementia. Consistent with a previous study ${ }^{(16)}$, an inverse association between fish consumption and the onset of dementia was observed, suggesting the potential benefits of fish intake for dementia prevention. Although the HR value of 0.84 might not be so large, its clinical impact would be large enough. We estimated the population attributable fraction (PAF) due to fish intake in the quartile 1 through quartile 3. The PAF was 5.6\% 
Table 6. Results of stratified analyses (participants with missing data were excluded)* (Adjusted hazard ratios and $95 \%$ confidence intervals)

\begin{tabular}{|c|c|c|c|c|c|c|c|c|}
\hline & & & Quartiles & ish co & nsumption & & & \\
\hline & Q1 (lowest) & & Q2 & & Q3 & & 4 (highest) & $P_{\text {for trend }} t$ \\
\hline Sex & & & & & & & & \\
\hline Male $(n 5859)$ & & & & & & & & \\
\hline Person-years & 6913 & & 4443 & & 7687 & & 9781 & \\
\hline No. of incident dementia & 134 & & 71 & & 122 & & 141 & \\
\hline Incidence rate/1000 person-years & $19 \cdot 4$ & & 16 & & $15 \cdot 9$ & & $14 \cdot 4$ & \\
\hline Multivariate-adjusted model $\neq$ & 1.00 & $0.91 \S$ & $0.68,1.22$ & 0.84 & $0.65,1.08$ & 0.82 & $0.64,1.06$ & 0.104 \\
\hline Female $(n 7243)$ & & & & & & & & \\
\hline Person-years & 8623 & & 3470 & & 13765 & & 10249 & \\
\hline No. of incident dementia & 202 & & 61 & & 222 & & 165 & \\
\hline Incidence rate/1000 person-years & $23 \cdot 4$ & & $17 \cdot 6$ & & $16 \cdot 1$ & & $16 \cdot 1$ & \\
\hline Multivariate-adjusted model & 1.00 & 0.92 & $0.68,1.22$ & 0.88 & $0.72,1.08$ & 0.87 & $0.69,1.09$ & 0.175 \\
\hline Age & & & & & & & & \\
\hline$<75$ years $(n 7753)$ & & & & & & & & \\
\hline Person-years & 9758 & & 5284 & & 13686 & & 12433 & \\
\hline No. of incident dementia & 78 & & 42 & & 78 & & 74 & \\
\hline Incidence rate/1000 person-years & 8 & & $7 \cdot 9$ & & $5 \cdot 7$ & & 6 & \\
\hline Multivariate-adjusted modelll & 1.00 & 1.06 & $0.73,1.56$ & 0.78 & $0.57,1.08$ & 0.88 & $0.63,1.22$ & 0.232 \\
\hline$\geq 75$ years $(n 5349)$ & & & & & & & & \\
\hline Person-years & 5778 & & 2629 & & 7767 & & 7597 & \\
\hline No. of incident dementia & 258 & & 90 & & 266 & & 232 & \\
\hline Incidence rate/1000 person-years & $44 \cdot 7$ & & $34 \cdot 2$ & & $34 \cdot 2$ & & $30 \cdot 5$ & \\
\hline Multivariate-adjusted modellI & 1.00 & 0.83 & $0.65,1.06$ & 0.84 & $0.71,1.01$ & 0.82 & $0.68,0.995$ & 0.042 \\
\hline $\begin{array}{l}\text { Green and yellow vegetables and } \\
\text { fruit consumption volume } \\
\quad<\text { median }(n 5326)\end{array}$ & & & & & & & & \\
\hline Person-years & 8431 & & 4072 & & 8412 & & 5400 & \\
\hline No. of incident dementia & 185 & & 66 & & 139 & & 84 & \\
\hline Incidence rate/1000 person-years & 21.9 & & $16 \cdot 2$ & & $16 \cdot 5$ & & $15 \cdot 6$ & \\
\hline Multivariate-adjusted model & 1.00 & 0.88 & $0 \cdot 66,1 \cdot 17$ & 0.87 & $0.70,1.09$ & 0.95 & $0.73,1 \cdot 23$ & 0.438 \\
\hline$\geq$ median $(n 5331)$ & & & & & & & & \\
\hline Person-years & 4091 & & 2668 & & 9136 & & 11054 & \\
\hline No. of incident dementia & 75 & & 43 & & 102 & & 145 & \\
\hline Incidence rate/1000 person-years & $18 \cdot 3$ & & $16 \cdot 1$ & & $11 \cdot 2$ & & $13 \cdot 1$ & \\
\hline Multivariate-adjusted model & 1.00 & 1.06 & $0.72,1.55$ & 0.66 & $0.49,0.89$ & 0.74 & $0.56,0.98$ & 0.012 \\
\hline Education level & & & & & & & & \\
\hline$<16$ years $(n 3619)$ & & & & & & & & \\
\hline Person-years & 4485 & & 2054 & & 5364 & & 5049 & \\
\hline No. of incident dementia & 140 & & 49 & & 130 & & 99 & \\
\hline Incidence rate/1000 person-years & $31 \cdot 2$ & & 23.9 & & $24 \cdot 2$ & & $19 \cdot 6$ & \\
\hline Multivariate-adjusted model ${ }^{\star \star}$ & 1.00 & 0.85 & $0.61,1 \cdot 18$ & 0.96 & $0.75,1.23$ & 0.81 & $0.61,1.08$ & 0.240 \\
\hline$\geq 16$ years $(n 8854)$ & & & & & & & & \\
\hline Person-years & 10271 & & 5567 & & 15148 & & 14156 & \\
\hline No. of incident dementia & 169 & & 72 & & 181 & & 183 & \\
\hline Incidence rate/1000 person-years & $16 \cdot 5$ & & $12 \cdot 9$ & & 11.9 & & $12 \cdot 9$ & \\
\hline Multivariate-adjusted model ${ }^{* *}$ & 1.00 & 0.89 & $0.67,1.17$ & 0.74 & $0.60,0.92$ & 0.83 & $0.67,1.04$ & 0.048 \\
\hline Time spent walking & & & & & & & & \\
\hline$<1 \mathrm{~h} / \mathrm{d}(n 9587)$ & & & & & & & & \\
\hline Person-years & 11286 & & 5533 & & 15244 & & 13238 & \\
\hline No. of incident dementia & 269 & & 96 & & 274 & & 222 & \\
\hline Incidence rate/1000 person-years & 23.8 & & $17 \cdot 4$ & & 18 & & $16 \cdot 8$ & \\
\hline Multivariate-adjusted model†† & 1.00 & 0.86 & $0.68,1.09$ & 0.88 & $0.74,1.05$ & 0.87 & $0.72,1.05$ & 0.146 \\
\hline$\geq 1 \mathrm{~h} / \mathrm{d}(n 3515)$ & & & & & & & & \\
\hline Person-years & 3905 & & 2238 & & 5765 & & 6304 & \\
\hline No. of incident dementia & 62 & & 33 & & 58 & & 75 & \\
\hline Incidence rate/1000 person-years & $15 \cdot 9$ & & $14 \cdot 7$ & & $10 \cdot 1$ & & 11.9 & \\
\hline Multivariate-adjusted model†† & 1.00 & 0.92 & $0.60,1.41$ & 0.65 & $0.45,0.95$ & 0.66 & $0.46,0.96$ & 0.014 \\
\hline Sleep duration & & & & & & & & \\
\hline$\leq 6 \mathrm{~h} / \mathrm{d}(n 2554)$ & & & & & & & & \\
\hline Person-years & 3600 & & 1673 & & 4344 & & 3416 & \\
\hline No. of incident dementia & 59 & & 18 & & 49 & & 35 & \\
\hline Incidence rate/1000 person-years & $16 \cdot 4$ & & $10 \cdot 8$ & & 11.3 & & $10 \cdot 2$ & \\
\hline Multivariate-adjusted modelł‡ & 1.00 & 0.74 & $0.43,1.27$ & 0.61 & $0.41,0.90$ & 0.65 & $0.42,1.01$ & 0.020 \\
\hline $7-8 \mathrm{~h} / \mathrm{d}(n 7531)$ & & & & & & & & \\
\hline Person-years & 8766 & & 4549 & & 12627 & & 12029 & \\
\hline No. of incident dementia & 175 & & 69 & & 168 & & 149 & \\
\hline Incidence rate/1000 person-years & 20 & & $15 \cdot 2$ & & 13.3 & & $12 \cdot 4$ & \\
\hline Multivariate-adjusted model $\ddagger \ddagger$ & 1.00 & 0.87 & $0.66,1.16$ & 0.81 & $0.65,1.01$ & 0.75 & $0.60,0.96$ & 0.014 \\
\hline
\end{tabular}


Table 6. (Continued)

\begin{tabular}{|c|c|c|c|c|c|c|c|c|}
\hline & \multicolumn{7}{|c|}{ Quartiles of fish consumption } & \multirow[b]{2}{*}{$P_{\text {for trend }} \dagger$} \\
\hline & \multicolumn{2}{|l|}{ Q1 (lowest) } & \multirow[t]{2}{*}{ Q2 } & \multicolumn{2}{|r|}{ Q3 } & \multicolumn{2}{|c|}{ Q4 (highest) } & \\
\hline \multicolumn{8}{|l|}{ Sleep duration } & \\
\hline \multicolumn{9}{|l|}{$7-8 \mathrm{~h} / \mathrm{d}(n 7531)$} \\
\hline Person-years & 8766 & & 4549 & & 12627 & & 12029 & \\
\hline No. of incident dementia & 175 & & 69 & & 168 & & 149 & \\
\hline Incidence rate/1000 person-years & 20 & & $15 \cdot 2$ & & $13 \cdot 3$ & & $12 \cdot 4$ & \\
\hline Multivariate-adjusted model $\ddagger \ddagger$ & 1.00 & 0.87 & $0.66,1.16$ & 0.81 & $0.65,1.01$ & 0.75 & $0.60,0.96$ & 0.014 \\
\hline \multicolumn{9}{|l|}{$\geq 9 \mathrm{~h} / \mathrm{d}(n 2808)$} \\
\hline Person-years & 2925 & & 1609 & & 4149 & & 4292 & \\
\hline No. of incident dementia & 100 & & 42 & & 113 & & 111 & \\
\hline Incidence rate/1000 person-years & $34 \cdot 2$ & & $26 \cdot 1$ & & $27 \cdot 2$ & & $25 \cdot 9$ & \\
\hline Multivariate-adjusted model $\ddagger \ddagger$ & 1.00 & 0.88 & $0.61,1.28$ & 1.00 & $0.75,1.33$ & 1.04 & $0.78,1.41$ & 0.707 \\
\hline $\begin{array}{l}\text { * Analyses by the Cox proportional hazards } \\
\text { † Probability value for trend was computed by } \\
\text { † Adjusted for the same covariates in model } \\
\S \text { Adjusted hazard ratios and } 95 \% \mathrm{Cl} \text { (all suc } \\
\text { ॥ Adjusted for the same covariates in model } \\
\text { I Adjusted for the same covariates in model } \\
\star \star \text { Adjusted for the same covariates in model } \\
\text { †† Adjusted for the same covariates in model } \\
\text { † Adjusted for the same covariates in model }\end{array}$ & $\begin{array}{l}\text { el. } \\
\text { tering the expos } \\
\text { Table } 2 \text { besides } \\
\text { lues). } \\
\text { Table } 2 \text { besides } \\
\text { Table } 2 \text { besides } \\
\text { Table } 2 \text { beside } \\
\text { f Table } 2 \text { beside } \\
\text { f Table } 2 \text { beside }\end{array}$ & $\begin{array}{l}\text { catego } \\
\text { x. } \\
\text { e. } \\
\text { een and } \\
\text { ducation } \\
\text { me spe } \\
\text { leep du }\end{array}$ & $\begin{array}{l}\text { ries as a contin } \\
\text { yellow vegetak } \\
\text { level. } \\
\text { nt walking. }\end{array}$ & $\begin{array}{l}\text { Is term } \\
\text { and fr }\end{array}$ & $\begin{array}{l}\text { (score variable } \\
\text { uit consumption }\end{array}$ & 2, 3 or & 4) in the Cox & \\
\hline
\end{tabular}

which suggests that $5.6 \%$ of dementia would have been prevented if all participants had consumed the similar volume of fish in the quartile 4 group, meaning about 2.6 million dementia would be prevented worldwide. Preventing 2.6 million people from dementia would bring huge benefit on our society in terms of quality of life, caregiver burden, costs for medical and longterm care.

In our main analyses, 1300 respondents were excluded because of a lack of fish consumption data, which might have introduced selection bias into our results. To take these participants into account, we re-analysed 14402 individuals after multiple imputations. In this case, the association between fish consumption and incident dementia did not change substantially, suggesting that our findings were unlikely to have been affected by selection bias.

The results from different Cox models suggested that after adjusting for dietary factors (i.e. green and yellow vegetable, fruits), the impact of fish consumption on incident dementia attenuated. Previous studies ${ }^{(36,37)}$ have suggested that vegetables (especially green leafy vegetables, which are good sources of folate, vitamin $\mathrm{E}$ and carotenoids) have protective effects against dementia and cognitive decline. Regarding fruits, a previous study also reported that a higher intake of citrus fruits (which was adjusted in our analyses) was associated with a lower risk of incident dementia ${ }^{(38)}$. Since participants with higher fish intake also consumed more fruits and vegetables, we consider that dietary food intake as a whole (i.e. the dietary pattern) has a stronger influence on dementia prevention than any single food component.

Stratified analyses showed that the associations between fish consumption and incident dementia did not differ by confounding factors but did with sleep duration (7-8 or $\geq 9 \mathrm{~h} / \mathrm{d}$ ). Previous studies have reported that longer sleep duration can be a preclinical symptom of dementia ${ }^{(39,40)}$, but it remains to be established how the relation between fish consumption and dementia is interacted by sleep duration.
As with previous studies, the present study had inconsistent conclusions. One previous study with an average follow-up of 9 years showed a non-significant association between incident risk of dementia and fish intake ${ }^{(4)}$, while two other studies with relatively shorter follow-up durations showed inconsistent results (one study with a mean follow-up of $2 \cdot 1$ years showed an inverse association ${ }^{(16)}$, while another with a mean followup of 5.4 years reported no association $\left.{ }^{(15)}\right)$. In addition, in a study that evaluated both short-term $(0-8$ years after a dietary assessment) and long-term (9-14 years after a dietary assessment) dementia risk in relation to fish intake, a moderately but non-significantly decreased risk of dementia was observed only with the shorter follow-up ${ }^{(17)}$. Reverse causality is generally considered a reason for this; however, reverse causality had little influence on our results because we excluded individuals who developed dementia in the first 2 years of follow-up and selected only individuals who had better cognitive function at baseline. Another possible reason for the different results between different studies might be that, in studies with longer term follow-up, there is more time for advances in medicine, and the participants with higher dementia risk who had been eating less fish are well treated, especially in regard to antihypertensive, antithrombotic and lipid-modifying therapies. Therefore, the differences across fish consumption subgroups in the risk of incident dementia became difficult to be observed (such an assumption has also been suggested in research on fish and $n-3$ fatty acid consumption and cardiovascular events $\left.{ }^{(41)}\right)$.

Moreover, previous studies only considered a few confounding factors (mainly age, sex, BMI and energy intake). In addition, those studies were conducted in Western countries, where fish is usually prepared by frying, compared with in Japan, where fish is usually consumed raw, or after steaming, boiling, stewing or grilling. There is evidence that deep fat frying can significantly deplete the $n-3$ fatty acids contained in fish ${ }^{(42)}$.

Compared with previous studies, the present work had several strengths. First, the number of participants ( $n$ 13 102) 
was by far the largest reported so far (previous range 488-8085). Second, we adjusted for many covariates. Third, almost all of the participants were followed up (99.1\%). Finally, the range of fish consumption in our study was markedly wider.

A few limitations should also be noted. First, since we did not evaluate the causes of dementia, the mechanism by which incident dementia was prevented by fish consumption remains unclear. Second, as we obtained fish consumption data only at baseline, some of the study participants may have changed their fish intake during follow-up. Third, we could not completely preclude potential and residual diet-related confounding factors because diet quality could not be fully considered by the FFQ. Fourth, the relatively short follow-up period might have compromised our results; for this reason, cohort studies with a longer follow-up should be conducted. Fifth, because the correlations between the participants' diet records and the FFQ for fish consumption were not very strong, an attenuation of relative risks towards the null hypothesis may have been caused by non-differential misclassification ${ }^{(43)}$. Therefore, the association observed in the present study may have been underestimated. Sixth, among 23091 valid responses, 6333 were excluded because they did not agree to provide written consent for review of their LTCI information. These individuals tended to have poorer health status and worse lifestyle-related behaviours (online Supplementary Table S1). Finally, only non-disabled elderly individuals (aged $\geq 65$ years) were included in the present study. Therefore, the findings obtained may not be generalisable to the Japanese population as a whole.

In conclusion, we identified an association between higher fish consumption and a lower risk of incident dementia among healthy elderly people without disability. These results suggest that habitual fish intake may be beneficial for the prevention of dementia.

\section{Acknowledgements}

We would like to thank Yoshiko Nakata, Miyuki Takeuchi, Yuko Miyoshi, Miho Imaizumi and Mami Takahashi for their technical assistance.

This research was funded by the NARO Bio-oriented Technology Research Advancement Institution (advanced integration research for agriculture and interdisciplinary fields). None of the funding organisations or sponsors was involved in the study design; in the collection, analysis or interpretation of data; in the writing of the report or in the decision to submit the article for publication.

I. T. designed the research; Y. T. and I. T. conducted the research; N. T. analysed the data; N. T. wrote the paper; S. Z., Y. T., S. A., Y. S., S. M. and I. T. provided constructive suggestions; and N. T. had primary responsibility for the final content. All authors read and approved the final manuscript for submission.

All authors have no conflicts of interest to declare.

\section{References}

1. Alzheimer's Disease International (2015) World Alzheimer Report 2015: The Global Impact of Dementia. https://www. alz.co.uk/research/world-report-2015

2. Cabinet Office, Government of Japan (2017) Situation on ageing: current state and trends on the elderly and their environment. Annual Report on the Ageing Society. https://www8. cao.go.jp/kourei/english/annualreport/2018/2018pdf_e.html

3. Morris MC, Evans DA, Bienias JL, et al. (2003) Consumption of fish and $n$-3 fatty acids and risk of incident Alzheimer disease. Arch Neurol 60, 940-946.

4. Schaefer EJ, Bongard V, Beiser AS, et al. (2006) Plasma phosphatidylcholine docosahexaenoic acid content and risk of dementia and Alzheimer disease: the Framingham Heart Study. Arch Neurol 63, 1545-1550.

5. Ono K \& Yamada M (2012) Vitamin A and Alzheimer's disease. Geriatr Gerontol Int 12, 180-188.

6. Lee HP, Casadesus G, Zhu X, et al. (2009) All-trans-retinoic acid as a novel therapeutic strategy for Alzheimer's disease. Expert Rev Neurotherapeut 9, 1615-1621.

7. Moore E, Mander A, Ames D, et al. (2012) Cognitive impairment and vitamin $\mathrm{B}_{12}$ : a review. Int Psychogeriatr 24, 541-556.

8. Whyte EM, Mulsant BH, Butters MA, et al. (2002) Cognitive and behavioral correlates of low vitamin $\mathrm{B}_{12}$ levels in elderly patients with progressive dementia. Am J Geriatric Psych 10, 321-327.

9. Masoumi A, Goldenson B, Ghirmai S, et al. (2009) $1 \alpha$, 25-Dihydroxyvitamin $\mathrm{D}_{3}$ interacts with curcuminoids to stimulate amyloid-beta clearance by macrophages of Alzheimer's disease patients. J Alzheimers Dis 17, 703-717.

10. La Fata G, Weber P \& Mohajeri MH (2014) Effects of vitamin E on cognitive performance during ageing and in Alzheimer's disease. Nutrients 6, 5453-5472.

11. Ellwanger JH, Franke SI, Bordin DL, et al. (2016) Biological functions of selenium and its potential influence on Parkinson's disease. An Acad Bras Cienc 88, 1655-1674.

12. Tomata Y, Sugiyama K, Kaiho Y, et al. (2016) Dietary patterns and incident dementia in elderly Japanese: the ohsaki cohort 2006 study. J Gerontol A Biol Sci Med Sci 71, 1322-1328.

13. Petersson SD \& Philippou E (2016) Mediterranean diet, cognitive function, and dementia: a systematic review of the evidence. Adv Nutr 7, 889-904.

14. Hosking DE, Eramudugolla R, Cherbuin N, et al. (2019) MIND not Mediterranean diet related to 12-year incidence of cognitive impairment in an Australian longitudinal cohort study. Alzheimers Dement 15, 581-589.

15. Huang TL, Zandi PP, Tucker KL, et al. (2005) Benefits of fatty fish on dementia risk are stronger for those without APOE epsilon4. Neurology 65, 1409-1414.

16. Kalmijn S, Launer LJ, Ott A, et al. (1997) Dietary fat intake and the risk of incident dementia in the Rotterdam Study. Ann Neurol 42, 776-782.

17. Devore EE, Grodstein F, van Rooij FJ, et al. (2009) Dietary intake of fish and omega-3 fatty acids in relation to long-term dementia risk. Am J Clin Nutr 90, 170-176.

18. Barberger-Gateau P, Raffaitin C, Letenneur L, et al. (2007) Dietary patterns and risk of dementia: the Three-City cohort study. Neurology 69, 1921-1930.

19. Government of Japan, Fishery Agency (2010) Trend of consumption of fishery products. White Paper on Fisheries. http://www. jfa.maff.go.jp/j/kikaku/wpaper/pdf/2010_haku_en6.pdf

20. Kuriyama S, Nakaya N, Ohmori-Matsuda K, et al. (2010) The Ohsaki Cohort 2006 study: design of study and profile of participants at baseline. J Epidemiol 20, 253-258. 
21. Ogawa K, Tsubono Y, Nishino Y, et al. (2003) Validation of a food-frequency questionnaire for cohort studies in rural Japan. Public Health Nutr 6, 147-157.

22. Kessler RC, Andrews G, Colpe LJ, et al. (2002) Short screening scales to monitor population prevalences and trends in nonspecific psychological distress. Psycholog Med 32, 959-976.

23. Kessler RC, Green JG, Gruber MJ, et al. (2010) Screening for serious mental illness in the general population with the K6 screening scale: results from the WHO World Mental Health (WMH) survey initiative. Int J Methods Psych Res 19, Suppl. 1, 4-22.

24. Meguro K \& Team. KP (2012) The validity of the basic checklist in the old-old population: the kurihara project. Jpn J Geriatr Psych 23, 725-730.

25. Ikeda A, Yamagishi K, Tanigawa T, et al. (2008) Cigarette smoking and risk of disabling dementia in a Japanese rural community: a nested case-control study. Cerebrovas Dis 25, 324-331.

26. Ikegami N (1997) Public long-term care insurance in Japan. JAMA 278, 1310-1314.

27. Tsutsui T \& Muramatsu N (2005) Care-needs certification in the long-term care insurance system of Japan. J Am Geriatr Soc 53 522-527.

28. Imahashi K, Kawagoe M, Eto F, et al. (2007) Clinical status and dependency of the elderly requiring long-term care in Japan. Toboku J Exp Med 212, 229-238.

29. Moriyama Y, Tamiya N, Kamimura A, et al. (2014) Doctors' Opinion papers in long-term care need certification in Japan: comparison between clinic and advanced treatment hospital settings. Public Policy Adminis Res 4, 31-37.

30. Okumura Y, Kuze J \& Higuchi K (2009) Prevalence of problematic behaviors in the ambulant elderly with dementia. Kawasaki J Med Welfare 15, 27-35.

31. Meguro K, Tanaka N, Kasai M, et al. (2012) Prevalence of dementia and dementing diseases in the old-old population in Japan: the Kurihara Project. Implications for Long-Term Care Insurance data. Psychogeriatrics 12, 226-234.

32. Yamamoto T, Kondo K, Hirai H, et al. (2012) Association between self-reported dental health status and onset of dementia: a 4-year prospective cohort study of older Japanese adults from the Aichi Gerontological Evaluation Study (AGES) Project. Psychosom Med 74, 241-248.

33. Hisano S (2009) The relationship between revised Hasegawa Dementia Scale (HDS-R), Mini-Mental State Examination (MMSE) and Bed-fast Scale, Dementia scale. Jpn I Geriatr Psych 20, 883-891.

34. Liu Y \& De A (2015) Multiple imputation by fully conditional specification for dealing with missing data in a large epidemiologic study. Int J Stat Med Res 4, 287-295.

35. So Y, Lin G \& Johnston G (2014) Using the PHREG procedure to analyze competing-risks data. SAS Global Forum. https:// support.sas.com/rnd/app/stat/papers/2014/competingrisk 2014.pdf

36. Morris MC (2012) Nutritional determinants of cognitive aging and dementia. Proc Nutr Soc 71, 1-13.

37. Morris MC, Booth S, Dawson-Hughes B, et al. (2015) Relations to cognitive change with age of micronutrients found in green leafy vegetables. FASEB $J \mathbf{2 9}, 260-263$.

38. Zhang S, Tomata Y, Sugiyama K, et al. (2017) Citrus consumption and incident dementia in elderly Japanese: the Ohsaki Cohort 2006 Study. Br J Nutr 117, 1174-1180.

39. Lu Y, Sugawara Y, Zhang S, et al. (2018) Changes in sleep duration and the risk of incident dementia in the elderly Japanese: the Ohsaki Cohort 2006 Study. Sleep 41, zsy143.

40. Benito-Leon J, Bermejo-Pareja F, Vega S, et al. (2009) Total daily sleep duration and the risk of dementia: a prospective population-based study. Eur J Neurol 16, 990-997.

41. Kromhout D, Giltay EJ \& Geleijnse JM (2010) n-3 Fatty acids and cardiovascular events after myocardial infarction. New Engl J Med 363, 2015-2026.

42. Candela M, Astiasarán I \& Bello J (1998) Deep-fat frying modifies high-fat fish lipid fraction. J Agric Food Chem $\mathbf{4 6}$, 2793-2796.

43. Dosemeci M, Wacholder S \& Lubin JH (1990) Does nondifferential misclassification of exposure always bias a true effect toward the null value? Am J Epidemiol 132, 746-748. 